\title{
Sociodemographic determinants in Alzheimer's disease - A retrospective study
}

\author{
S. Kant ${ }^{1, *}$, Karan Poddar ${ }^{2}$, M. Kamle ${ }^{3}$, C. Patil ${ }^{4}$ \\ Consultant, ${ }^{1,2}$ Neurology Clinic, Varanasi, Uttar Pradesh, ${ }^{3}$ Kamle Clinic, Vikroli, Mumbai, Maharashtra, ${ }^{4}$ Vardhman Clinic, \\ Thane, Maharashtra, India
}

*Corresponding Author:

Email: drskpoddar@gmail.com

\begin{abstract}
Introduction: Alzheimer's disease (AD) is a common cognitive function disorder commonly reported in old ages. Our aim was to understand the sociodemographic factors associated with AD.

Material and Methods: In a retrospective study, we screened database at our private memory clinic to include the adult patients $>45$ years of age who were screened with Montreal Cognitive Assessment (MoCA) test for AD. MoCA score of $<26$ was considered for diagnosis of AD.

Results: In 2412 patients included in analysis, 91.9\% patients were diagnosed with AD. Overall mean age of the participants was $53.5 \pm 6.8$ years and $63.2 \%$ were males. Among sociodemographic factors, compared to patients without AD, those with AD were younger $(\mathrm{p}=0.006)$, females $(\mathrm{p}<0.001)$, had lower level of education $(\mathrm{p}<0.001)$, had unskilled occupation like being housewife or farmer ( $\mathrm{p}<0.001)$, Muslim by religion $(\mathrm{p}=0.001)$, and reported to have more than 5 members in family $(\mathrm{p}<0.001)$. Alcohol addiction was associated with lesser occurrence of $\mathrm{AD}(\mathrm{p}=0.001)$. No difference by dietary pattern was evident $(\mathrm{p}=0.976)$.

Conclusion: In an urban memory clinic setting, AD is observed in young and female patients who have lower level of education and are involved in unskilled occupation. Greater number of family members also predisposes to AD. These findings need further confirmation in a prospective and long duration follow up.
\end{abstract}

Keywords: Alzheimer's disease, Sociodemographic, Cognitive dysfunction, India, Memory.

\section{Introduction}

Alzheimer's dementia is one of the most common form of cognitive dysfunction. ${ }^{1}$ From the diagnosis to complete dependency for the activities of daily living occurs in 8 to 10 years. ${ }^{2,3}$ Progression of AD is inevitable and in the severe form, $\mathrm{AD}$ is associated with severe cognitive impairment, inability to dress, eat, and wash, institutionalization, and eventually results in death. ${ }^{4}$ However, the prognosis in $\mathrm{AD}$ varies in each patient and the disease course is often difficult to predict. This necessitates assessment of factors associated with $\mathrm{AD}$ progression to take measures to improve patient care and thereby prognosis. The factors like sociodemographic factors like low level of education, clinical factors presence of depression and genetic polymorphisms like APOE $\varepsilon 4$ carriers are associated with early onset of AD. ${ }^{5}$ Among sociodemographic factors, younger age and greater level of education were reported as predictor of rapid $\mathrm{AD}$ progression. ${ }^{4}$

In Indian context, AD is commonly encountered. A 10-year prospective follow-up study reported $\mathrm{AD}$ incidence rate of 11.67 per 1000 person-years in adults aged $\geq 55$ years with rates increasing to 15.54 in patients aged $\geq 65$ years. ${ }^{6}$ Observations from South India suggest increasing dementia with increasing age, low education and female gender. ${ }^{7}$ Age, therefore an important contributor to the $\mathrm{AD}$. Early onset dementia is reported to be the one with onset before the age of 65 years which can present with atypical symptoms. ${ }^{8}$ However, there is relative lack of studies assessing the dementia in populations below 60 years of age. Further, given the high rates of dementia in population above 55 years of age in India, $\mathrm{AD}$ onset may occur much earlier than expected. Therefore, to understand the occurrence of $\mathrm{AD}$ in younger population, we assessed patients aged 45 years and above for $\mathrm{AD}$ and studied the association of $\mathrm{AD}$ with various socio-demographic parameters.

\section{Material and Methods}

Study setting: The study was conducted at tertiary level private memory clinic catering to urban and semi-urban population in North India. This private centre is involved in providing super-speciality services in Neurology and is equipped with required set-up.

Study design: This study is a retrospective, observational study of patient database screened for AD.

Study duration: The database was screened for inclusion of patients for over 45 years duration. Patients encountered in Jan 2015 to Dec 2017 year duration were taken in to analysis.

Study population: In this study, adult participants above the age of 45 years who were screened for Alzheimer's dementia were included.

Study instrument: In our memory clinic, we screen patients using Montreal Cognitive Assessment (MoCA) test. MoCA test has advantage of being able to diagnose even the mild cognitive impairment. MoCA test has been reported to be sensitive. MoCA scale administration usually takes 10 minutes and maximum score is 30.(9) A cut-off of score less than 26 was considered as cognitive impairment. This threshold is reported to provide optimal diagnostic accuracy of the MoCA scale.(10) 
Patients with AD diagnosis were considered as group A and without $\mathrm{AD}$ as group $\mathrm{B}$.

Study methodology: From the database, we captured patients' data in to Microsoft spreadsheet. Demographic data like age, gender, religion, occupation, education level, marital status, number of family members, diet and addiction were noted. Age was further categorized in groups as age $<50,51$ to 60,61 to 70 , and $>70$ years. Education level was categorized in four categories as illiterate, primary, secondary plus higher secondary and graduate. Number of family members were categorized in three categories as <5, 5-8 and $>8$. By diet, participants were categorized as pure vegetarian who never ate meat in any form or as mixed vegetarian who ate some form of meat.

Assessment: The study assessment was the association of various socio-demographic factors with presence or absence of AD.

\section{Statistical Analysis}

We used Microsoft spreadsheet to assimilate the data from our database and was analysed with SPSS software version 15. Categorical data was presented as frequency and percentages whereas continuous data was presented as mean and standard deviation. We used Chi square test for assessing statistical significance in categorical parameters whereas student t-test was applied to test significance in continuous parameters. $\mathrm{P}$ value less than 0.05 was considered significant.

\section{Results}

In total, 2412 adult patients visiting to our clinic were screened for $\mathrm{AD}$ over period 3 years between Jan 2015 and Dec 2017. Table 1 enlists the baseline characteristic of overall study population. Mean age of the study participants was $53.5 \pm 6.8$ years. Most patients were from age group of 45 to 50 years $(55.4 \%)$ followed by 51 to 60 years $(31.9 \%)$ and 61 to 70 years $(10.9 \%)$. Only $1.7 \%$ of them were above the age of 70 years. Nearly $2 / 3^{\text {rd }}$ cases were males $(63.2 \%)$ and $36.8 \%$ were females. Education level of patient suggested that $36.3 \%$ being illiterate whereas primary education was seen in $5.1 \%, 43.6 \%$ had secondary or higher secondary level of education and $14.9 \%$ were graduate. By occupation, housewives (37.7\%) were the most commonly encountered in this study. $14.7 \%$ were in service and $22.3 \%$ were farmers. Over half-of the study participants (56.9\%) revealed that they had 5 to 8 family members in their families. Except for one participant, all were married. $47.6 \%$ were vegetarian by diet whereas $35.1 \%$ reported some addiction.

Table 1: Baseline characteristics

\begin{tabular}{|l|c|}
\hline \multicolumn{1}{|c|}{ Parameter } & $\begin{array}{c}\text { Observation } \\
(\mathbf{n = 2 4 1 2})\end{array}$ \\
\hline Age (Years) & \\
\hline Mean \pm SD & $53.5 \pm 6.8$ \\
\hline Age groups (\%) & \\
\hline
\end{tabular}

\begin{tabular}{|l|c|}
\hline $45-50$ & $1336(55.4)$ \\
\hline $51-60$ & $770(31.9)$ \\
\hline $61-70$ & $264(10.9)$ \\
\hline $71-80$ & $42(1.7)$ \\
\hline Sex $(\%)$ & \\
\hline Male & $1525(63.2)$ \\
\hline Female & $887(36.8)$ \\
\hline Education level & \\
\hline Illiterate & $876(36.3)$ \\
\hline Primary & $124(5.1)$ \\
\hline $\begin{array}{l}\text { Secondary and higher } \\
\text { secondary }\end{array}$ & $1052(43.6)$ \\
\hline Graduate & $360(14.9)$ \\
\hline Occupation & \\
\hline Housewife & $909(37.7)$ \\
\hline Business & $611(25.3)$ \\
\hline Farmer & $537(22.3)$ \\
\hline Service & $355(14.7)$ \\
\hline Number of family members & \\
\hline$<5$ & $454(18.8)$ \\
\hline $5-8$ & $1373(56.9)$ \\
\hline$>8$ & $585(24.3)$ \\
\hline Marital status & \\
\hline Married & $2411(99.96)$ \\
\hline Unmarried & $1(0.04)$ \\
\hline Religion & \\
\hline Hindu & $2230(92.46)$ \\
\hline Muslim & $181(7.50)$ \\
\hline Christian & $1(0.04)$ \\
\hline Diet & $1147(47.6)$ \\
\hline Vegetarian & $1265(52.4)$ \\
\hline Mixed & $847(35.1)$ \\
\hline Addiction & \\
\hline presed & \\
\hline
\end{tabular}

Data presented as mean \pm SD or frequency $(\%)$

Based on MoCA scale score, the AD was seen in nearly $92 \%$ cases (Fig. 1). The association of AD with various sociodemographic parameters is shown in Table 2. Mean age of patients in group A was significantly lower than patients in group B $(53.4 \pm 6.6$ vs $54.7 \pm 7.7$ respectively, $\mathrm{p}=0.006$ ). Similarly, most patients in group A were below 60 years of age $(88.1 \%)$ than group B (78.6\%). The difference in proportion of patient among different age groups was significant in two study groups $(\mathrm{p}<0.001)$. Among patients in group A, $60.8 \%$ were males and $39.2 \%$ were females. The difference in proportion of patients for presence or absence of $\mathrm{AD}$ was significant for the gender $(\mathrm{p}<0.001)$. Being illiterate was associated with $\mathrm{AD}(39.4 \%)$ or having higher education was associated with lower incidence of $\mathrm{AD}(10.6 \%)$. The difference among different level of education was significant $(p<0.001)$. Possibility of AD was more in Muslim religion as compared to Hindu religion. The difference in proportions was significant $(\mathrm{p}<0.001)$. Lesser number of family members to $<5$ were found to be associated with lower incidence of $\mathrm{AD}(17.9 \%)$ 
compared to higher number of family members including 5 to $8(57.9 \%)$ and over $8(24.2 \%)$. The difference in proportions compared to patients in group $B$ was significant $(p<0.01)$. Proportion of patients with alcohol addiction was significantly lower in group A than $\mathrm{B}(34.1 \%$ vs $46.4 \%, \mathrm{p}=0.001)$.

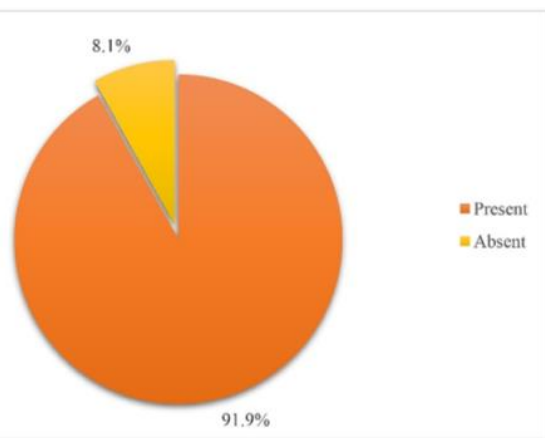

Fig. 1: Prevalence of Alzheimer's disease

Table 2: Comparative characteristics of patients with or without Alzheimer's disease

\begin{tabular}{|c|c|c|c|}
\hline \multirow[t]{2}{*}{ Parameter } & \multicolumn{2}{|c|}{ Alzheimer's disease } & \multirow[t]{2}{*}{ P value } \\
\hline & $\begin{array}{l}\text { Present - Group } \\
\text { A }(n=2216)\end{array}$ & $\begin{array}{c}\text { Absent - Group B } \\
(\mathbf{n}=196)\end{array}$ & \\
\hline Age & $53.4 \pm 6.6$ & $54.7 \pm 7.7$ & 0.006 \\
\hline \multicolumn{4}{|l|}{ Age groups } \\
\hline $45-50$ & $1252(56.5)$ & $84(42.9)$ & \multirow[t]{4}{*}{$<0.001$} \\
\hline $51-60$ & $700(31.6)$ & $70(35.7)$ & \\
\hline $61-70$ & $226(10.2)$ & $38(19.4)$ & \\
\hline $71-80$ & $38(1.7)$ & $4(2.0)$ & \\
\hline \multicolumn{4}{|l|}{ Sex } \\
\hline Male & $1347(60.8)$ & $178(90.8)$ & \multirow[t]{2}{*}{$<0.001$} \\
\hline Female & $869(39.2)$ & $18(9.2)$ & \\
\hline \multicolumn{4}{|l|}{ Education } \\
\hline Illiterate & $873(39.4)$ & $3(1.5)$ & \multirow[t]{4}{*}{$<0.001$} \\
\hline Primary & $124(5.6)$ & 0 & \\
\hline $\begin{array}{l}\text { Secondary } \\
\text { and higher } \\
\text { secondary }\end{array}$ & 984 (44.4) & $68(34.7)$ & \\
\hline Graduate & $235(10.6)$ & $125(63.8)$ & \\
\hline \multicolumn{4}{|l|}{ Occupation } \\
\hline Housewife & $891(40.2)$ & $18(9.2)$ & \multirow[t]{4}{*}{$<0.001$} \\
\hline Farmer & $517(23.3)$ & $20(10.2)$ & \\
\hline Business & $545(24.6)$ & $66(33.7)$ & \\
\hline Service & $263(11.9)$ & $92(46.9)$ & \\
\hline \multicolumn{4}{|l|}{ Religion } \\
\hline Hindu & $2043(92.2)$ & $187(95.4)$ & \multirow[t]{3}{*}{0.001} \\
\hline Muslim & $173(7.8)$ & $8(4.1)$ & \\
\hline Christian & 0 & $1(0.5)$ & \\
\hline \multicolumn{4}{|l|}{$\begin{array}{l}\text { Number of } \\
\text { family } \\
\text { members }\end{array}$} \\
\hline$<5$ & $396(17.9)$ & 58 (29.6) & $<0.001$ \\
\hline $5-8$ & $1283(57.9)$ & $90(45.9)$ & \\
\hline$>8$ & $537(24.2)$ & $48(24.5)$ & \\
\hline \multicolumn{4}{|l|}{ Diet } \\
\hline Vegetarian & 1054 (47.6) & $93(47.4)$ & \multirow[t]{2}{*}{0.976} \\
\hline Mixed & $1162(52.4)$ & $103(52.6)$ & \\
\hline Addiction & $756(34.1)$ & $91(46.4)$ & 0.001 \\
\hline
\end{tabular}

Data presented as mean \pm SD or frequency $(\%)$

\section{Discussion}

This observation at a private memory clinic identified that Alzheimer's dementia is common in
Indian setting. In relatively healthy adults above 45 years of age, AD was observed in $91.9 \%$ cases after assessment using MoCA test. A recent meta-analysis on 
global prevalence of dementia reported crude prevalence rate of $4.7 \%$ in subjects above 65 years of age with expected increase to $85 \%$ by $2030 .{ }^{11}$ In a study from Alladi et al. from Southern India reported AD as most common form of dementia with prevalence of $38.3 \%$. Further, they reported that $49.9 \%$ patients had early onset dementia. ${ }^{12}$ The prevalence of dementia in different regions in India are reported to vary widely which could be due to use of different methodologies and instruments applied for screening and diagnosis, differences in defining the criteria, impact of environmental and cultural differences. ${ }^{13}$

Multiple factors are the determinants of AD. In our clinic-based study, sociodemographic factors like young age, female gender, lower level of education, unskilled occupation like housewife or farmer, being Muslim by religion, having higher number of family members were associated with $\mathrm{AD}$. Compared most of the previously done studies, we included young ages ( $>45$ years) in this study. Mean age of the participants with AD in our study was 53.4 years which is much less compared to report of Alldi et al., reporting mean age of 66.3 years at presentation. ${ }^{12}$ In a study from Italy, among sociodemographic factors, Musicco et al., observed faster $\mathrm{AD}$ progression in younger age and more educated participants. ${ }^{4}$ Females were found to have more association with $\mathrm{AD}$ than males. Study form India reported increasing $\mathrm{AD}$ with increasing age with rates of $0.62 \%$ in individuals aged $>55$ and $1.07 \%$ in those who were $>65$ years. No association with gender or literacy was reported. ${ }^{14} \mathrm{~A}$ report from Hebert et al., after 11 years follow-up observed no significant difference by gender in age-specific incidence of $\mathrm{AD}$. They further suggested that the greater prevalence observed in women is probably because of longer life expectancy as against any gender specific risk factors when compared to men. ${ }^{15}$ This suggests that age and gender can have differential impact on incidence of AD. It should be noted that $\mathrm{AD}$ pathology might start in early age demanding screening of younger population for AD. Also, patients with early-onset AD may not present with classical memory related symptoms. Kodeam et al., reported non-memory symptoms in one-third of early onset $\mathrm{AD}$ (mean age $56 \pm 5$ years) compared to only $6 \%$ in late onset $\mathrm{AD}$ (mean age $74 \pm 6$ years) with significant difference in the proportion of patients $(\mathrm{p}<0.001)$.

A lower level of education was associated with $\mathrm{AD}$ in our study. In a study from Brazil, Bacalho et al., reported lower level of education to be associated with $\mathrm{AD}$ which is similar to our observation. ${ }^{5}$ But, findings from Musicco et al., suggested faster AD progression in more educated participants. ${ }^{4}$ Stern et al., reported that patients of $\mathrm{AD}$ having higher level of education had increased mortality after adjusting for age, gender, and clinical dementia rating. ${ }^{16}$ These findings suggest that though patient with lower education have early diagnosis of $\mathrm{AD}$, higher levels of education may present with more severe $\mathrm{AD}$ and can have adverse outcome. Therefore, education is important factor in determining the $\mathrm{AD}$ and $\mathrm{AD}$ should be carefully evaluated patients with both high and low level of education.

We further observed $\mathrm{AD}$ in unskilled occupation like housewife or farmers as compared to serviceman. Mortel et al., reported education with occupation as best predictor of $\mathrm{AD}$ suggesting increased risk of $\mathrm{AD}$ in patients low levels of educational and occupational achievement. ${ }^{17}$ Another study observed association of manual work like tailors, dressmakers, house constructers, carpenters, mechanical technicians, farmers, typographers, welders, and metal workers with increased risk of $\mathrm{AD} .{ }^{18}$ Therefore, having some more skilled occupation might lower the risk of AD. This association needs to be further evaluated in a prospective, randomized study.

Though we observed an association of Muslim religion with $\mathrm{AD}$ there are no studies reporting difference in incidence of $\mathrm{AD}$ by religion. However, spirituality and religious activities are reported to slow cognitive decline and help patients to deal in a better way with the disease which can add to improved quality of life. ${ }^{19}$ Furthermore, a more number of family members (>5) were found to be associated with development of AD. No previous studied have reported any such association and therefore demands further investigation.

An interesting finding in our study that alcohol addiction was not associated with greater prevalence of $\mathrm{AD}$. This is in line with findings from a meta-analysis which reported that alcohol drinking in late life is associated with reduced risk of dementia although the mechanisms for the same remain unclear. ${ }^{20}$ This demands further investigation in to the pathophysiology of alcohol drinking and $\mathrm{AD}$.

\section{Conclusion}

This observation in a memory clinic suggest that in adults with age above 45 years, screening of $\mathrm{AD}$ should be instituted to diagnose it early as there may be nonmemory symptoms of AD. Among sociodemographic factors, young age was associated with AD suggesting early onset of $\mathrm{AD}$ in Indian population. Gender differences need further evaluation. Low level of education and unskilled occupation have association with AD. However, education can mask the severity of memory impairment and may present with severe dysfunction at the time of diagnosis of AD. Additionally religion and number of family members can determine the incidence of $\mathrm{AD}$. Therefore, this large retrospective evaluation suggests significant role of sociodemographic factors in occurrence of AD in India.

\section{References}

1. Plassman BL, Langa KM, Fisher GG, Heeringa SG, Weir DR, Ofstedal MB, et al. "Prevalence of dementia in the United States: The aging, demographics, and memory study". Neuroepidemiol 2007;29:125-32.

2. Larson EB, Shadlen M-F, Wang L, Mccormick WC, Bowen JD, Teri L et al. "Survival after Initial Diagnosis 
of Alzheimer Disease". Ann Internal Med 2004;140:5019.

3. Brookmeyer R, Corrada MM, Curriero FC, Kawas C "Survival Following a Diagnosis of Alzheimer Disease". Arch Neurol 2002;59:1764-7.

4. Musicco M, Palmer K, Salamone G, Lupo F, Perri R, Mosti S, et al. "Predictors of progression of cognitive decline in Alzheimer's disease : the role of vascular and sociodemographic factors". J Neurol 2009;256:1288-95.

5. Aparecida M, Bicalho C, Pimenta FA, Bastos-rodrigues L, Hansen ÉDO, Neves SC, et al. "Sociodemographic characteristics, clinical factors, and genetic polymorphisms associated with Alzheimer's disease". Int J Geriatr Psychiatry 2013;28:640-6.

6. Mathuranath PS, George A, Ranjith N, Justus S, Kumar MS, Menon R, et al. "Incidence of Alzheimer's disease in India: A 10 yearsfollow-up study". Neurol India 2012;6:625-30.

7. Mathuranath PS, Cherian PJ, Mathew R, Kumar S, Alexander A, Ranjith N, et al. "Dementia in Kerala, South India: prevalence and influence of age, education and gender". Int J Geriatr Psychiatry 2010;25:290-7.

8. Koedam ELGE, Lauffer V, van der Vlies AE, van der Flier WM, Scheltens P, Pijnenburg YAL. "Early-Versus Late-Onset Alzheimer's Disease: More than Age Alone". J Alzheimer's Dis 2010;19:1401-8.

9. Nasreddine ZS, Phillips NA, Bedirian V, Charbonneau S, Whitehead V, Collin I. "The Montreal Cognitive Assessment, MoCA: a Brief Screening Tool for Mild Cognitive Impairment". J Am Geriatr Soc 2005;53:695-9.

10. Larner AJ. "Screening utility of the Montreal Cognitive Assessment ( MoCA ): in place of--or as well as--the MMSE?". Int Psychogeriatr 2012;24:391-6.

11. Prince M, Bryce R, Albanese E, Wimo A, Ribeiro W, Ferri CP. "The global prevalence of dementia: A systematic review and metaanalysis". Alzheimer's Dement 2013;9:63-75.

12. Alladi S, Mekala S, Chadalawada SK, Jala S, Mridula R, Kaul S. "Subtypes of dementia: A study from a memory clinic in India". Dement Geriatr Cogn Disord 2011;32:32-8.

13. Das SK, Pal S, Ghosal MK. "Dementia : Indian scenario". Neurol India 2012;60:618-24.

14. Chandra V, Ganguli M, Pandav R, Johnston J, Belle S, Dekosky ST. "Prevalence of Alzheimer's disease and other dementias in rural India: The Indo-US study". Neurol 1998;51:1000-8.

15. Hebert LE, Scherr PA, Mccann JJ, Beckett LA, Evans DA. "Is the Risk of Developing Alzheimer's Disease Greater for Women than for Men?". Am J Epidemiol 2001;153:132-6.

16. Stern Y, Tang MX, Denaro J, Mayeux R. "Increased Risk of Mortahty in Alzheimer's Disease Patients with More Advanced Educational and Occupational Attainment". Ann Neurol 1995;37:590-5.

17. Mortel KF, Meyer JS, Herod B, Thornby J. "Education and Occupation as Risk Factors for Dementias of the Alzheimer and Ishcemic Vascular types". Dementia 1995;6:55-62.

18. Qiu C, Karp A, von Strauss E, Winblad B, Fratiglioni L, Bellander T. "Lifetime principal occupation and risk of Alzheimer's disease in the Kungsholmen Project". Am J Ind Med 2003;43:204-11.

19. Agli O, Bailly N, Ferrand C. "Spirituality and religion in older adults with dementia: A systematic review". Int Psychogeriatrics 2015;27:715-25.

20. Anstey KJ, Mack HA, Cherbuin N. "Alcohol consumption as a risk factor for dementia and cognitive decline: Meta-analysis of prospective studies". Am J Geriatr Psychiatry 2009;17:542-55. 